\title{
ALGUNS ASPECTOS DA RELAÇÃO ENTRE A TEORIA SAUSSURIANA DA LINGUAGEM E A TEORIA DO SIGNIFICANTE LACANIANO*
}

\author{
Sergio Augusto Franco Fernandes \\ $(\mathrm{UFRB})^{\dagger}$ \\ sergioaffernandes@gmail.com
}

Resumo: Faz-se necessário uma busca de elementos que venham a facilitar a compreensão das origens do significante lacaniano, na tentativa de esclarecer, pela via do estruturalismo lingüístico, até onde vai, realmente, a influência saussuriana. Sabe-se que o significante lacaniano, mesmo tendo como referência epistemológica o significante saussuriano, (não deve ser confundido). Normalmente se atribui a Ferdinand de Saussure a invenção da teoria do signo. Ressaltaremos, entretanto, que essa "invenção" é bem anterior às teorias do lingüista genebrino. Levaremos em conta as observações de JeanLuc Nancy e Philippe Lacoue-Labarthe, na medida em que esses autores demonstram que o deslocamento operado sobre o esquema saussuriano não vai depender, como comumente se pensa, da autonomia do significante. Verificaremos, portanto, até que ponto mostra-se legítimo o uso do termo significante na teoria lacaniana.

Palavras-chave: epistemologia, Lacan, linguagem, significante.

Inicialmente, vamos levar em consideração o que o lingüista Michel Arrivé (ARRIVÉ, 1999, p. 73) constata: que o significante lacaniano tem como referência epistemológica

\footnotetext{
" Artigo recebido em 21.03.2009 e aceito para publicação em 09.02.2010.

† Sergio Augusto Franco Fernandes é Professor Doutor na Universidade Federal do Recôncavo da Bahia, Santo Antônio de Jesus, Bahia, Brasil.
} 
o significante saussuriano, que o significante lacaniano não deve ser confundido com o significante saussuriano e, por fim, que apesar das diferenças, ambos significantes estão vinculados por relações tais, que a denominação significante mostra-se legítima. Vamos tentar compreender. Arrivé se diz persuadido de que Lacan conhecia bem um outro lingüista, um dinamarquês chamado Louis Hjelmslev, autor de Prolégomènes a une théorie du langage, publicação de 1943 (HJELMSLEV, 1971), cuja única menção ao seu nome é encontrada no índice dos seus Escritos (LACAN, 1998, p. 928). Hjelmslev, com efeito, dedicou-se, sobretudo, aos aspectos metodológicos da lingüística, na tentativa de fazer da ciência da língua uma disciplina isenta de quaisquer pressupostos metafísicos. No seu entender, a lingüística deveria conter a menor quantidade possível de proposições implícitas, tendo cada pesquisador que definir, com o máximo de rigor, todos os conceitos que viesse a utilizar. Talvez tenha surgido daí a desconfiança de Arrivé de que o Saussure que Lacan havia lido fosse carregado de influências de Hjelmslev, embora, para a maioria dos estudiosos, seja ponto pacífico que o Saussure lido por Lacan seja um Saussure muito mais "à la Jakobson".

Entretanto, foi com Henri Delacroix, na sua obra Le langage et la pensée (DELACROIX, 1930), que Lacan encontrou, pela primeira vez, já em 1931, uma referência ao nome e à reflexão de Saussure, silenciando, por mais de vinte anos, acerca dessa descoberta. Com a palavra, Roudinesco: "Não resta qualquer dúvida, portanto, de que foi sob a pena desse autor (Delacroix), hoje esquecido, que Lacan descobriu pela primeira vez a teoria saussuriana da língua, da qual fará um uso tão fecundo duas décadas mais 
tarde" (ROUDINESCO, 1994, p. 43). De acordo com a autora, a referência a esse livro, publicado em 1930, fornece uma indicação de grande valor sobre as leituras do jovem Lacan. Delacroix (que havia sido professor de filosofia de Jean-Paul Sartre), para fundamentar a sua argumentação sobre a afasia, teria se baseado no Curso de lingüistica geral (SAUSSURE, 2006), publicado na Suíça em 1915 e, na França, em 1916.

Somente em 1954, na sua aula de 23 de junho, intitulada "De locutionis significatione" (LACAN, 1993, p. 280296), traduzida pelo Padre Beirnaert por "De la signification de la parole" (Da significação da fala), que Lacan pronunciou em público o nome de Saussure. Aplica à sua teoria do signo alguns comentários apoiados na autoridade de Benveniste, outro lingüista tratado, até então, com a maior reverência. Antes de passar a palavra ao Padre Beirnaert para discorrer sobre Santo Agostinho, Lacan comenta, de forma bastante pertinente, tanto a questão da distinção entre o significado e a coisa, quanto a questão do problema da natureza do significante, demonstrando, assim, que leu com atenção o trecho da obra de Saussure que trata do problema da materialidade ou da formalidade do significante:

Donde desembocamos nesta verdade absolutamente manifesta da nossa experiência, e que os lingüistas sabem bem, de que toda significação não faz senão reenviar a uma outra significação. Também os lingüistas tomaram o seu partido, e é no interior desse campo que desde então desenvolvem a sua ciência.

Não se deve crer que isso prossiga sem ambigüidade, e que, para um Ferdinand de Saussure, que o viu claramente, as definições tenham sempre sido dadas de maneira perfeitamente satisfatória.

O significante é o material audível, o que nem por isso quer dizer o som. Entretanto, nem por isso, tudo que é da ordem da fonética é 
incluído na lingüística enquanto tal. É do fonema que se trata, quer dizer, do som em oposição a outro som, no interior de um conjunto de oposições (LACAN, 1993a, p. 281).

Nos Escritos, o nome de Saussure aparece, pela primeira vez, no texto "A coisa freudiana ou o sentido do retorno a Freud em psicanálise”, de 1956 (LACAN, 1998 p. 415). Numa determinada passagem, Lacan alfineta um outro Saussure (Raymond) ${ }^{1}$ ao mesmo tempo em que exalta a figura do pai, Ferdinand, dizendo que este Saussure, sim, deveria ser considerado fundador da lingüística moderna. Após essa referência, podemos dizer que houve um "florescimento" saussuriano na obra de Lacan na medida em que ele, o próprio Lacan, estabeleceu uma conexão entre a sua leitura de Freud e a reflexão dos lingüistas Saussure e, principalmente, Roman Jakobson. Vale lembrar que o alcance da oposição entre significante e significado somente é verificado com a descoberta freudiana. No que diz respeito à relação entre Saussure e Freud, comenta Arrivé (ARRIVÉ, 1999) que, para Lacan, é como se, sozinho, Saussure fosse incompleto, só encontrando a sua "perfeição" num encontro futuro com Freud.

Inicialmente, Lacan, sem hesitar, reconhece a origem saussuriana da sua teoria do significante, chegando mesmo a reivindicar esse modelo como sendo aquele que lhe inspirou, tomando-o como fundamento epistemológico. Com o passar do tempo, a atitude lacaniana em relação ao referido modelo vai se modificando na medida em que o psicanalista francês diminui a importância do modelo saussuriano mesmo nas suas especulações. Numa passagem do Seminário I, Lacan critica os lingüistas, dizendo que estes demoraram 
quinze séculos para redescobrir idéias que já se encontravam em Santo Agostinho:

Tudo que acabo de dizer a vocês sobre o significante e o significado está lá, desenvolvido com uma lucidez sensacional, tão sensacional que temo que os comentadores espirituais que se entregaram à sua exegese não tenham sempre visto toda a sutileza dele. Acham que o profundo Doutor da Igreja se perde em coisas bem fúteis. Essas coisas fúteis não são nada além do que há de mais agudo no pensamento moderno sobre a linguagem (LACAN, 1993a, p. 282).

Os Estóicos aparecem, também, como antecessores da lingüística saussuriana, como atesta uma passagem de Televisão (LACAN, 1993b, p. 23), texto de 1974. Nessa passagem, Saussure é reduzido ao simples papel de tradutor dos termos latinos. Antes, porém, por volta de 1964-1965, Lacan já havia feito essa constatação, ao se referir não à moral estóica, mas, sim, à lógica e à dialética desses antigos. Vamos tentar esclarecer. Não é difícil notar que, normalmente, é atribuída a Saussure a invenção da teoria do signo. Acontece que essa "invenção" é bem anterior às teorias do lingüista genebrino, pertencendo, na realidade, aos Estóicos. Mayette Viltar (VILTAR 2004, p. 97) constata que Jakobson, a partir de 1966, passou a ironizar esse equívoco, qual seja, de atribuir a Saussure essa "nova descoberta". Jakobson, sem atacar diretamente Saussure, ironiza o tanto de louvor dirigido à suposta "novidade" da interpretação do signo, em especial a do signo verbal como unidade indissolúvel de dois constituintes: o significante e o significado. Para Jakobson (JAKOBSON 2001), toda a questão da relação, ao mesmo tempo abstrata e concreta entre significante e significado, já se encontrava claramente exposta.

De acordo com Viltar, caso Saussure tivesse se apoiado na teoria estóica, certamente não teria se distanciado tanto 
da questão do arbitrário do signo. Benveniste foi outro lingüista que, ao criticar a noção saussuriana do arbitrário do signo, também não fez a devida referência aos Estóicos. Ainda segundo a autora, quando Benveniste tira as conseqüências do fato de que o objeto real situa-se fora da relação significante-significado, ainda assim, ele não está separado da maneira pela qual os Estóicos estabeleceram a teoria do signo. Constatada a referência aos antigos, Viltar discorre acerca dos prováveis motivos do "desdém" aos mesmos:

Entretanto, o século XIX não amou os Estóicos. De um modo mais geral, tem-se pensado quase em todos os tempos que o ensino dos Estóicos, pedante e estéril, não valia nada. Sua reabilitação foi promovida por Lukasiewicz, em 1934, que tornou efetivo o estudo da ligação dos Estóicos com a lógica moderna. E pelo desenvolvimento da lógica no século XX, eles encontram progressivamente sua importância. Se Prantl fala de sua "estupidez sem limites", de seu "formalismo imbecil"; se Zeller lhes atribui um formalismo gramatical indigente e estéril, etc., não é somente porque os textos estóicos eram de acesso difícil, sob todos os pontos de vista (VILTAR, 2004, p. 101).

Como dissemos, foi por volta de 1964-1965 que Lacan veio a fazer uma referência à lógica e à dialética estóicas, ironizando aqueles que, por sua vez, faziam referência ao significante como "lacaniano":

[...] que não data, seguramente, nem de Saussure nem de Troubetzkoy, nem de Jakobson, essa teoria do significante que os Estóicos, e nomeadamente por exemplo um Crisipo, já tinham levado a um extremo ponto de perfeição: Signans e Signatum já estão em circulação há uns dois mil anos (LACAN, 1965, p. 211)2.

Entretanto, além de Santo Agostinho e dos Estóicos, Saussure teria também como antecessor ninguém menos do que o próprio Freud. Ao menos é o que diz Lacan em "A 
instância da letra no inconsciente ou a razão desde Freud" (LACAN, 1998, p. 516), ao constatar que "todos" desconheciam o papel constitutivo do significante, presente desde a descoberta do inconsciente por Freud. Nesse sentido, podemos pensar em colocar "A interpretação dos sonhos”, publicada em 1900, à frente das formalizações da lingüística. Com efeito, do ponto de vista anacrônico, Saussure, Jakobson e toda a lingüística teriam sido antecipados pelas idéias freudianas. Segundo Arrivé, o que vem a explicar essa "antecipação" de Freud sobre Saussure e toda a lingüística seria a própria elaboração dos vínculos entre linguagem e inconsciente: "Se a linguagem é, de fato, a condição do inconsciente, como poderia ocorrer que o teórico do inconsciente não abrisse o caminho para a lingüística?" (ARRIVÉ, 1999, p. 79). Nessa perspectiva, o autor se mostra em acordo com Lacan.

Mas são com os comentários minuciosos de Jean-Luc Nancy e Philippe Lacoue-Labarthe a respeito de "A instância da letra no inconsciente ou a razão desde Freud" (LACAN, 1998) que se tornam evidentes as diferenças entre Saussure e Lacan. Apesar das diferenças e do distanciamento, Lacan não vai deixar de render homenagens ao lingüista. Diz que o que vai marcar a lingüística como disciplina é o momento constitutivo de um algoritmo que a funda, a saber, S/s, que se lê: significante sobre significado, onde o "sobre" vai corresponder à barra que separa as duas etapas. Lacan, então, faz a sua homenagem:

O signo assim redigido merece ser atribuído a Ferdinand de Saussure, embora não se reduza estritamente a essa forma em nenhum dos numerosos esquemas em que aparece na impressão das diversas aulas dos três cursos, dos anos de 1906-7, 1908-9 e 1910-11, que a devoção de um grupo de seus discípulos reuniu sob o título 
Curso de lingüística geral: publicação primordial para transmitir um ensino digno desse nome, isto é, que só pode ser detido em seu próprio movimento (LACAN, 1998, p. 500).

A formalização $\mathrm{S} / \mathrm{s}$ (significante sobre significado) caracterizou para Lacan, diante de uma diversidade de escolas, a etapa moderna da lingüística. Lacan tratava de visar, na lingüística aberta por Saussure, a ciência da letra, única ciência que, do seu ponto de vista, poderia convir a uma teoria do sujeito. Vale a ressalva de que Lacan designa a letra como sendo "[...] este suporte material que o discurso concreto toma emprestado da linguagem" (LACAN, 1998, p. 498). Tal ciência não deixa de estar relacionada com a lingüística, ao menos enquanto a teoria do sujeito deva submeter-se a uma teoria da linguagem. Trata-se, nesse sentido, de uma teoria do sujeito sem relação com qualquer antropologia ou psicologia: "[...] é bem da lingüística que procede a ciência do sujeito para ir-se constituindo progressivamente" (LACOUE-LABARTHE e NANCY, 1991, p. 40).

Para termos uma noção do conceito de ruptura epistemológica ao qual Lacan implicitamente faz referência, J.-L. Nancy e P. Lacoue-Labarthe sugerem que designemos de forma precisa o algoritmo, tomando-o como um processo constitutivo de uma lógica, onde as expressões "lógica algorítmica" e "lógica simbólica" se equivalham. Ressaltam que estão a se referir ao algoritmo como conceito, no sentido epistemológico. Contudo, o que se percebe é que o signo saussuriano termina por passar por um certo tratamento: "Algoritmizar o signo, se é que se pode arriscar tal expressão, será o mesmo, praticamente, que impedi-lo de funcionar como signo. Digamos mesmo que, em o colocando, o 
estaremos destruindo" (LACOUE-LABARTHE e NANCY, 1991, p. 42). Para os autores da citação, é o algoritmo que Lacan vai dizer que merece ser atribuído a Ferdinand de Saussure e, não necessariamente, o signo.

Com efeito, o que na perspectiva de J.-L. Nancy e P. Lacoue-Labarthe realmente subverte de ponto a ponto a concepção saussuriana do signo é a radical separação do significante e do significado por uma barreira resistente à significação. Lacan vai dizer: "A temática dessa ciência, por conseguinte, está efetivamente presa à posição primordial do significante e do significado, como ordens distintas e inicialmente separadas por uma barreira resistente à significação" (LACAN, 1998, p. 500). Em Saussure, onde a relação (ou reciprocidade) marca um início, Lacan introduz uma resistência tal que a transposição da barra (relação significante/significado), isto é, a produção da própria significação, jamais será evidente. Todavia, o deslocamento operado sobre Saussure não vai depender, como comumente se pensa, da autonomia do significante. Esta fica como secundária, na medida em que ela depende da própria resistência: "O que é primordial (e fundador) é, de fato, a barra" (LACOUE-LABARTHE e NANCY, 1991, p. 44). Conforme os dois autores, o corte por meio do qual se instaura a ciência da letra nada mais é do que o corte introduzido no signo.

Em relação ao signo, na perspectiva dos nossos dois autores, o que se passa a questionar não é mais o tema do arbitrário, e, sim, uma maneira de se ter colocado essa questão, qual seja, a do tratamento da linguagem que é imposto por uma certa posição do arbitrário. Sendo o signo arbitrário, torna-se, então, quase impossível ir além do re- 
conhecimento do vínculo estabelecido entre o significante e o significado. Seria então nesse reconhecimento que a lingüística, na sua totalidade, permaneceria presa. Vale a ressalva de que Lacan não vai culpar de forma direta Saussure, mas, sim, as emendas posteriores feitas ao texto, as quais não se pode afirmar que tenham sido conseqüência da própria cientificidade do lingüista. Com efeito, a linguagem não mais deve ser pensada a partir do signo

E fracassaremos em sustentar sua questão enquanto não nos tivermos livrado da ilusão de que o significante atende à função de representar o significado, ou, melhor dizendo: de que o significante tem que responder por sua existência a título de uma significação qualquer (LACAN, 1998, p. 501).

Enfim, vamos tentar compreender, agora, encerrando essas considerações que dizem respeito a uma epistemologia do significante lacaniano, o papel e a função do algoritmo, ou seja, vamos ver em que sentido é necessário, por conseguinte, a "destruição" do signo, em razão de se ter que garantir a ciência da letra. Isso consiste, conforme J.-L. Nancy e P. Lacoue-Labarthe, em trabalhar o signo até destruir toda a sua função de representação, quer dizer, até aniquilar a sua própria relação de significação. Estaria aí o papel e a função do algoritmo: "O algoritmo não é o signo. Ou melhor: o algoritmo é o signo enquanto não significa (sobre o modo da representação do significado pelo significante)" (LACOUE-LABARTHE e NANCY, 1991, p. 47). Arriscamse os autores a dizer que o algoritmo seria o signo "cancelado", de preferência a dizer "destruído". A questão é que, uma vez instalado o corte no signo (a barra acentuada), toda a operação acaba por recair por sobre o significante. Discorrem os autores: 
[...] trata-se de fazer o significante sofrer um deslocamento tal que não se possa mais, doravante, tomá-lo como um elemento do signo, mas que seja preciso, debaixo do antigo nome, visar ou encarar um conceito (ao menos) paradoxal: aquele de um significante sem significação (LACOUE-LABARTHE e NANCY 1991, p. 47).

Essa seria, segundo nossos comentadores, a razão pela qual a operação consistiria em "fazer a diferença" entre o esquema do signo, atribuído a Saussure, e o esquema do algoritmo. Para J.-L. Nancy e P. Lacoue-Labarthe, isso provaria, de forma definitiva, que o algoritmo $\mathrm{S} / \mathrm{s}$ (significante sobre significado) não seria, como tal, comparável ao esquema saussuriano; apenas a sua ilustração, entretanto, seria comparável. Todavia, nada disso nos impede de afirmar a legitimidade do uso do termo significante por parte de Lacan (concordando com Arrivé), na medida em que, apesar de não nos apresentar com clareza as suas "origens", ele faz uma apropriação "consciente" e bastante profícua do significante mesmo, tanto para fundamentar quanto para desenvolver a sua teoria.

Abstract: A search of elements becomes necessary to facilitate the understanding of the origins of the Lacan's significant, in the attempt to explain through structural linguistic, the limits of the Saussure's influence. It is known that the Lacan's significant, even though has the Saussure's influence as a reference in epistemology, both "significant" must not be mistaken. It is usually attributed to Ferdinand de Saussure the invention of the theory of the linguistic sign. We will stand out, however, that this "invention" is previous to the theories of the genevan linguist. We will observe the comments of Jean-Luc Nancy and Philippe Lacoue-Labarthe, to the point where these authors demonstrate that the displacement operated on the Saussure's scheme will not depend on, as it is well known, the significant's autonomy. It will be verified, therefore, how legitimate it is, the use of the significant's term in the Lacan's theory.

Key words: epistemology, Lacan, language, significant. 


\section{NOTAS}

1 Raymond de Saussure (1894-1971) é filho do lingüista Ferdinand de Saussure (1857-1913). Nasceu na Suíça, fez análise com Freud, tornando-se um dos fundadores da Sociedade Psicanalítica de Paris e um dos pioneiros na divulgação das idéias de Freud na França e na Suíça francesa. Foi também um dos fundadores da Federação Européia de Psicanálise, em 1966.

2 Seminário inédito - tradução nossa.

\section{REFERÊNCIAS}

ARRIVÉ, M. Linguagem e psicanálise, lingüística e inconsciente. Freud, Saussure, Pichon, Lacan. Tradução de Lucy Magalhães. Rio de Janeiro: JZE, 1999.

DELACROIX, H. Le langage et la pensée. Paris: Félix Alcan, 1930.

HJELMSLEV, L. Prolégomènes à une théorie du langage. Paris: Minuit, 1971.

JAKOBSON, R. Lingüística e comunicação. São Paulo: Cultrix, 2001.

LACAN, J. O Seminário, livro 1, Os escritos técnicos de Freud (1953-54). Tradução de Betty Milan. Rio de Janeiro: JZE, 1993a.

- Televisão (1974). Tradução de Antonio Quinet. Rio de Janeiro: JZE, 1993b.

- Escritos. Tradução de Vera Ribeiro. Rio de Janeiro: JZE, 1998. 
- Le Séminaire de Jacques Lacan, livre XII, Problèmes cruciaux pour la psychanalyse. Sessão de 7 de abril de 1965 (inédito).

LACOUE-LABARTHE, P. e NANCY, J.-L. O título da letra. Tradução de Sergio Joaquim de Almeida. São Paulo: Escuta, 1991.

ROUDINESCO, E. Jacques Lacan. Esboço de uma vida, história de um sistema de pensamento. Tradução de Paulo Neves. São Paulo: Cia. das Letras, 1994.

SAUSSURE, F. Curso de lingüística geral. Tradução de A. Chelini, J. P. Paes e I. Blikstein. São Paulo: Pensamento/Cultrix, 2006.

VILTAR, M. Falar com as paredes. Notas sobre a materialidade do signo. In: Revista Literal, Campinas, $\mathrm{n} \underline{\mathrm{o}} 7$, 2004. (Tradução de Viviane Veras) 